\title{
Influence of Asian dust storms on air quality in Taiwan
}

\author{
Chung-Ming Liu *, Chea-Yuan Young ${ }^{b}$, Yen-Chih Lee ${ }^{a}$ \\ a Department of Atmospheric Sciences, National Taiwan University, Taipei, Taiwan, ROC \\ b Environmental Protection Administration, Taipei, Taiwan, ROC
}

Received 28 August 2005; received in revised form 28 February 2006; accepted 21 March 2006

Available online 3 May 2006

\begin{abstract}
In each year, dust storms triggered by cold air masses passing through northern China and Mongolia enhance the PM10 concentration over Taiwan region during winter and spring. On average, there are four to five dust events and 6.1 dust days in a year in Taiwan. Each event lasts for 1 day or even longer. A procedure to identify a dust event is rationalized and exercised on data collected during 1994-2005. Also, a ranking method named as the dust intensity rank (DIR) is developed to distinguish the intensity of each event affecting the local air quality. About $86 \%$ of dust days belong to ranks 1 and 2 . In general, poorer air quality is associated with higher ranks. Ranks 4 and 5 correspond to a PSI (Pollution Standard Index) larger than 100. Linking DIR with the popular PSI is useful for both the public and the official forecasting system. It is also useful for inter-comparison between dust influences on air quality at different downstream regions in Taiwan. Composite analyses of the temporal and spatial variation of the hourly PM10 level indicate that dust particles usually arrive $12 \mathrm{~h}$ before the time of the peak PM10 concentration and last for $36 \mathrm{~h}$ at northern Taiwan, while the time of the peak concentration at eastern or western Taiwan, due to the evolution of the synoptic weather system, is about 3-12 h later. It is noted that the increase of PM10 level at the western side of Taiwan results from a mixture of upstream Asian dust inputs and local pollutants.
\end{abstract}

(C) 2006 Elsevier B.V. All rights reserved.

Keywords: Air quality; Dust storm; PM10; PSI; Indexing; Taiwan

\section{Introduction}

Dust storms happen every year over most of eastern Asia. Are the air-borne coarse crust-originated particles harmful to human health? Kwon et al. (2002) explored the effect of Asian dust events on daily mortality in Seoul, South Korea, during the period of 1995-1998, and showed that the association between the dust events and deaths from cardiovascular and respiratory causes was strong enough to indicate that people with advanced

\footnotetext{
* Corresponding author. Tel.: +886 2 23696291; fax: +886 2 23660412.

E-mail address: liucm@ntu.edu.tw (C.-M. Liu).
}

cardiovascular and respiratory disease might be susceptible to Asian dust events. Chen et al. (2004) assessed the possible effects of Asian dust storms on the mortality of the residents of Taipei, Taiwan, during the period 19952000. This study found greater specificity in associating dust effects with respiratory death. Lei et al. (2004) used pulmonary hypertensive rat models to examine inflammation markers in the lung and in the peripheral blood after an exposure to Asian dust storm particles. Their results revealed that an exposure to particulate matters during a dust event could increase lung inflammation and injury in pulmonary hypertensive rats. Clearly, besides the dramatic effects of dust particles on visibility (Kim et al., 2001; Chung et al., 2003), their potential influence on 
the health risk of the younger generation and allergies of elderly people cannot be ignored.

In Taiwan, impacts of dust storms on air quality studies were first suggested by Liu and Feng (1990) as a consequence of a study of atmospheric turbidity retrieved from the direct solar flux dataset, and then confirmed by the local air quality monitoring dataset (Young et al., 1997). Lin (2001) described a few events that happened in spring 2000 and succeeded in reproducing some key features of the long-range transport of dust through numerical simulations. The highest PM10 (particle diameter smaller than $10 \mu \mathrm{m}$ ) level noted by Lin (2001) was over $400 \mu \mathrm{g} \mathrm{m}^{-3}$ on 28 April 2000. In central Taiwan, Fang et al. (2002) observed the presence of dust particles and noted that the ratio of PM2.5 (particle diameter smaller than $2.5 \mu \mathrm{m}$ ) to PM10 was $60 \%$ before and after a dust storm period of 3-6 March 2001, but was lower than 50\% during that event period.

The visibility changes with the intensity of the dust storm that ranges from dust haze and blowing dust to weak, strong and a very strong dust storm (Qian et al., 1997; Qian et al., 2002). Such distinctions are applicable in locations near the dust source regions or in regions with frequent heavy dustfalls (Chen and Lim, 2004). In Korea, haze events are categorized into three levels: regular, severe and very severe according to surface visibility ranges of between $4-10 \mathrm{~km}, 2-4 \mathrm{~km}$ and 0 $2 \mathrm{~km}$, respectively (KMA, 2002). However, at locations far downstream, the effects of dust storms on deteriorating local air quality can be identified only by particle measurements. For instance, Chung et al. (2003) noted that the three record-breaking episodes, 21st-23rd March, 7th-10th April and 11th-12th November 2002, recorded hourly maximum PM10 concentrations of 3006, 2942 and $1106 \mathrm{~g} \mathrm{~m}^{-3}$, respectively, at Koonghyon in central Korea. Fang et al. (1999) noted a dust event causing high API (Air Pollution Index) in Hong Kong on 9th May 1996 and did inorganic and organic analyses of aerosol samples collected during this event. Lee and Hill (2003) identified spring dust episodes on 17th April 1998 and 28th-29th March 2000 in Hong Kong as characterized by high concentrations of $\mathrm{Al}, \mathrm{Fe}$, $\mathrm{Ca}, \mathrm{Mn}$ and $\mathrm{Mg}$, and an hourly maximum PM10 level of 267,327 and $349 \mu \mathrm{g} \mathrm{m}^{-3}$, respectively.

Therefore, a ranking methodology must be developed to rank the intensity of each dust event, named the dust intensity rank (DIR) hereafter, based on the measured hourly averaged PM10 level. It is useful to set up a climatological relationship between the event ranking level and the mean affected status of local air quality. For instance, each dust episode distinguishes itself by the peak dustfall, but the popular environmental health index PSI is developed for a 24-h average condition. A statistical relationship between DIR and PSI is therefore useful for both governmental officials and the public. Most of all, each dust storm can eventually develop into a widespread regional event; a commonly accepted DIR helps to inter-compare the influence of dust particles on the air quality of different areas.

In this paper, we have developed a ranking methodology based on the local air quality monitoring dataset and performed a systematic analysis of dust storm events that affected the air quality in Taiwan during 1994-2005 for the purpose of establishing a statistical relationship between dust events and the air quality affected. Hourly average air quality data provided by Taiwan EPA are used in this analysis. Among all species, PM10 level has been determined by the automatic Wedding $\beta$-gauge monitor (Yang, 2002).

\section{Identification of dust events}

Most of the cold fronts approaching Taiwan are initiated by a Siberian cold air mass passing through the northern China border. If this air mass has triggered dust storms over the desert regions along the border and then has moved swiftly southeastward, then the dust particles are carried by a high pressure system and drop over Taiwan after the passage of the guiding cold front. Therefore, each dustfall in Taiwan happens after the frontal rainfall, which is associated with a prevailing northeasterly and decrease in air temperature. Then the center of the cold high pressure system is approximately over central China and moving eastward to the East China Sea. Areas affected by the airflows coming from the eastern side of the center then shift accordingly; hence, the dustfall region moves from the northern to the eastern side of Taiwan. Area 1 in Fig. 1 has recorded the most frequent dustfalls. Areas with peak dustfall also move southward along the western coast. However, the blocking of the Central Mountain Range results in a stagnant condition at the central and southern sides of Taiwan and the dust particles are presumed to be well mixed with local pollutants.

In general, the increase of the PM10 concentration within a short period of time happens not only on dusty days. Local emissions are far more influential (Yang, 2002). However, on occasions when upstream crustal influences are important, a strong northeasterly prevails over northern Taiwan which suppresses significantly the level of primary pollutants, e.g. $\mathrm{CO}$ and $\mathrm{NO}_{\mathrm{x}}(=\mathrm{NO}+$ $\mathrm{NO}_{2}$ ). Meanwhile, due to the contributions from the lower troposphere over northern China and Mongolia, as suggested by Liu and Liu (1991), Akimoto et al. (1996) and Liu et al. (1997), the hourly ozone levels 


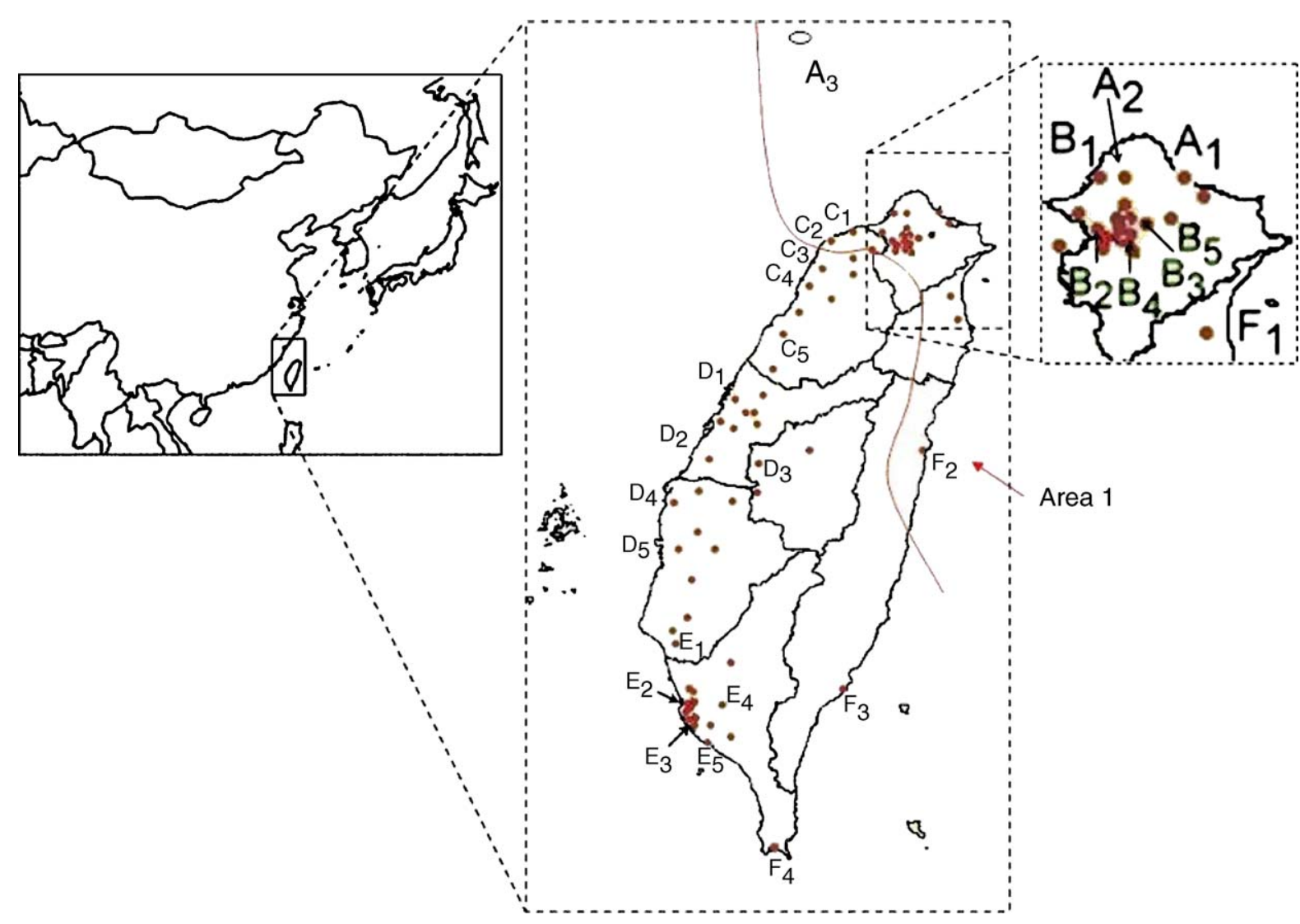

Fig. 1. There are 73 air quality monitoring sites (marked as red dots) in Taiwan. Stations $A_{1}-F_{4}$ are selected for analysis and are marked. Area 1 is noted as the major region affected by dustfalls from mainland China.

measured in Taiwan show a minor diurnal variation. Hence, to distinguish whether the upstream crustal inputs overtake the local contribution of pollutants at certain sites, a check of both the air quality and meteorology datasets is needed.

Furthermore, Wanli and Yanming stations (marked as $\mathrm{A}_{1}$ and $\mathrm{A}_{2}$ in Fig. 1) always lead other stations by detecting the first dustfall and peak PM10 level. Wanli, being at the seashore of the northern Taiwan coast, often registers a peak level (about $206 \mu \mathrm{g} \mathrm{m}^{-3}$ ) higher than that at Yanming (about $106 \mu \mathrm{g} \mathrm{m}^{-3}$ ), which is located $850 \mathrm{~m}$ above the sea level and $1 \mathrm{~km}$ south of Wanli. Many times, stratus clouds overlie the Yanming Mountain, as the northeasterlies bring moist air from the East China Sea to Taiwan. If a dust event occurs at the same time, dirty dark yellow cloud water is often collected at Yanming with a considerably low level of PM10 concentration (Lin and Peng, 1999).

In this paper, all local measurement datasets in 19942005 have been analyzed and mapped for the dust events as they occur. However, in spite of just checking local records, it is necessary to analyze the surface observation data of dust release from northern China in order to confirm whether there have been dust storm events occurred some days earlier, and to trace the movement of dust clouds by analyzing the synoptic weather maps, the satellite images of SeaWIFS or MODIS, the information retrieved from satellite in-situ instruments such as the TOMS aerosol index, and the backward air parcel trajectories, etc., so as to confirm the arrival of the dust particles. In some instances, air quality data in Taiwan show a signal of a dust arrival but those are pollutants coming from eastern China or from biomass burning sources in Southeast Asia (Fang et al., 2002).

In all, a total of 54 dust events are carefully identified in 1994-2005 and listed in Table 1. Each event has been identified with the first peak concentration occurring hour at Wanli or Yanming, which is named as the hour 0. Local time (LT) is used to indicate the time of peak occurrence. The peak PM10 concentration must be over $150 \mu \mathrm{g} \mathrm{m}^{-3}$, which is assigned by referring to the PSI system. For a daily average PM10 level of $150 \mathrm{\mu g} \mathrm{m}^{-3}$, the assigned sub-index is 100 , which is considered to be unhealthy. Furthermore, to distinguish the dust intensity from one event to another, a dust intensity rank (DIR) has been 
Table 1

Listing of the 54 dust events in which the air quality in northern Taiwan has been affected by Asian dust storms

\begin{tabular}{|c|c|c|c|c|c|c|c|c|c|c|c|c|c|c|c|}
\hline \# & Year & Month & Date & $\mathrm{LT}$ & $\begin{array}{l}\text { Average of three } \\
\text { highest PM10 } \\
\text { level in area } 1\end{array}$ & DIR & $\begin{array}{l}\# \text { of } \\
\text { PSI }>100\end{array}$ & \# & Year & Month & Date & $\mathrm{LT}$ & $\begin{array}{l}\text { Average of three } \\
\text { highest PM10 } \\
\text { level in area } 1\end{array}$ & DIR & $\begin{array}{l}\# \text { of } \\
\text { PSI }>100\end{array}$ \\
\hline 1 & 1994 & 1 & 27 & 1 & 185 & 1 & 0 & 28 & 2001 & 1 & 14 & 13 & 232 & 2 & 3 \\
\hline 2 & 1994 & 2 & 9 & 12 & 298 & 2 & 2 & 29 & 2001 & 2 & 1 & 14 & 172 & 1 & 0 \\
\hline 3 & 1994 & 2 & 21 & 22 & 172 & 1 & 0 & 30 & 2001 & 2 & 16 & 18 & 289 & 2 & 0 \\
\hline 4 & 1994 & 3 & 24 & 17 & 170 & 1 & 0 & 31 & 2001 & 3 & 2 & 12 & 180 & 1 & 1 \\
\hline 5 & 1995 & 2 & 28 & 15 & 211 & 2 & 1 & 32 & 2001 & 3 & 4 & 12 & 330 & 3 & 5 \\
\hline 6 & 1995 & 3 & 4 & 12 & 176 & 1 & 0 & 33 & 2001 & 3 & 7 & 10 & 202 & 2 & 0 \\
\hline \multirow[t]{2}{*}{7} & 1995 & 3 & 12 & 18 & 588 & 5 & 10 & 34 & 2001 & 3 & 28 & 12 & 264 & 2 & 0 \\
\hline & 1995 & 3 & 13 & 1 & 290 & 2 & 0 & 35 & 2001 & 4 & 12 & 9 & 322 & 3 & 10 \\
\hline \multirow[t]{2}{*}{8} & 1995 & 5 & 14 & 23 & 270 & 2 & 0 & 36 & 2002 & 1 & 1 & 22 & 173 & 1 & 0 \\
\hline & 1995 & 5 & 15 & 1 & 239 & 2 & 0 & & 2002 & 1 & 2 & 19 & 151 & 1 & 0 \\
\hline 9 & 1995 & 12 & 24 & 12 & 181 & 1 & 0 & 37 & 2002 & 1 & 7 & 20 & 159 & 1 & 1 \\
\hline \multirow[t]{4}{*}{10} & 1996 & 5 & 8 & 23 & 336 & 3 & 0 & 38 & 2002 & 1 & 21 & 21 & 170 & 1 & 0 \\
\hline & 1996 & 5 & 9 & 12 & 288 & 2 & 21 & 39 & 2002 & 2 & 11 & 22 & 327 & 3 & 5 \\
\hline & 1996 & 5 & 10 & 2 & 165 & 1 & 0 & 40 & 2002 & 3 & 8 & 15 & 152 & 1 & 0 \\
\hline & 1996 & 5 & 12 & 10 & 163 & 1 & 0 & 41 & 2002 & 3 & 18 & 22 & 160 & 1 & 0 \\
\hline 11 & 1997 & 1 & 2 & 3 & 245 & 2 & 0 & 42 & 2002 & 4 & 9 & 15 & 204 & 2 & 0 \\
\hline 12 & 1998 & 12 & 15 & 10 & 182 & 1 & 1 & & 2002 & 4 & 10 & 6 & 172 & 1 & 0 \\
\hline 13 & 1999 & 1 & 7 & 10 & 260 & 2 & 1 & 43 & 2003 & 1 & 23 & 11 & 165 & 1 & 0 \\
\hline 14 & 1999 & 1 & 15 & 19 & 171 & 1 & 0 & 44 & 2003 & 2 & 20 & 8 & 165 & 1 & 0 \\
\hline 15 & 1999 & 2 & 3 & 11 & 184 & 1 & 1 & 45 & 2003 & 3 & 22 & 7 & 172 & 1 & 0 \\
\hline 16 & 1999 & 2 & 12 & 16 & 152 & 1 & 0 & 46 & 2003 & 12 & 17 & 24 & 162 & 1 & 0 \\
\hline 17 & 1999 & 2 & 19 & 11 & 212 & 2 & 0 & & 2003 & 12 & 18 & 2 & 185 & 1 & 0 \\
\hline \multirow[t]{2}{*}{18} & 1999 & 4 & 6 & 17 & 324 & 3 & 0 & & 2003 & 12 & 19 & 18 & 178 & 1 & 0 \\
\hline & 1999 & 4 & 7 & 12 & 194 & 1 & 6 & 47 & 2003 & 12 & 25 & 24 & 166 & 1 & 1 \\
\hline 19 & 1999 & 4 & 13 & 12 & 167 & 1 & 0 & & 2003 & 12 & 26 & 2 & 303 & 3 & 0 \\
\hline 20 & 2000 & 2 & 26 & 14 & 207 & 2 & 0 & 48 & 2003 & 12 & 31 & 19 & 241 & 2 & 0 \\
\hline 21 & 2000 & 3 & 20 & 6 & 214 & 2 & 0 & & 2004 & 1 & 1 & 1 & 153 & 1 & 1 \\
\hline \multirow[t]{2}{*}{22} & 2000 & 3 & 24 & 15 & 336 & 3 & 14 & & 2004 & 1 & 2 & 22 & 154 & 1 & 0 \\
\hline & 2000 & 3 & 25 & 2 & 237 & 2 & 3 & 49 & 2004 & 2 & 5 & 18 & 187 & 1 & 0 \\
\hline 23 & 2000 & 3 & 29 & 10 & 271 & 2 & 15 & & 2004 & 2 & 6 & 17 & 170 & 1 & 0 \\
\hline \multirow[t]{2}{*}{24} & 2000 & 4 & 10 & 20 & 208 & 2 & 0 & 50 & 2004 & 2 & 15 & 12 & 184 & 1 & 0 \\
\hline & 2000 & 4 & 11 & 1 & 182 & 1 & 0 & 51 & 2004 & 3 & 6 & 9 & 153 & 1 & 0 \\
\hline \multirow[t]{2}{*}{25} & 2000 & 4 & 27 & 13 & 400 & 4 & 19 & 52 & 2004 & 4 & 2 & 20 & 202 & 2 & 0 \\
\hline & 2000 & 4 & 28 & 2 & 562 & 5 & 19 & & 2004 & 4 & 3 & 1 & 188 & 1 & 0 \\
\hline 26 & 2000 & 5 & 1 & 12 & 268 & 2 & 2 & 53 & 2004 & 12 & 8 & 15 & 202 & 2 & 0 \\
\hline \multirow[t]{2}{*}{27} & 2000 & 5 & 13 & 23 & 196 & 1 & 4 & 54 & 2005 & 3 & 18 & 7 & 234 & 2 & 1 \\
\hline & 2000 & 5 & 14 & 1 & 199 & 1 & 6 & & & & & & & & \\
\hline
\end{tabular}

The dust intensity rank (DIR) is assigned for each event based on the average value of three highest PM10 level in area 1. Also listed is the number of stations with PSI being larger than 100 in area 1. LT stands for local time.

developed. The average of the three highest PM10 peak levels measured at the 21 monitoring stations in area 1 (Fig. 1) is calculated for each dust event, with the constraint that the time of occurrence of the peak concentration at each selected station should be within $3 \mathrm{~h}$ after the hour 0 . Then, rank 1 is designated for days with the averaged PM10 concentration of the three peak levels being between 150 and $200 \mu \mathrm{g} \mathrm{m}^{-3}$, rank 2 for between 200 and $300 \mu \mathrm{g} \mathrm{m}^{-3}$, rank 3 for between 300 and $400 \mu \mathrm{g} \mathrm{m}^{-3}$, rank 4 for between 400 and $500 \mu \mathrm{g} \mathrm{m}^{-3}$, and rank 5 for higher than $500 \mu \mathrm{g} \mathrm{m}^{-3}$. Within those 54 dust events, $86 \%$ belong to ranks 1 and 2 . Since each event can last longer than 1 day, a total of 73 dust days are identified.
Area 1 in Fig. 1, with one-third of the nation's population, has been selected to represent the major dustinfluenced area, since the dust falls first at Wanli and Yanming, and then spreads over all area. Meanwhile, dust particles also fall onto the western coast, but due to a weaker prevailing airflow, contributions from the local pollutant emission should not be ignored. For DIR developed here, it is better to use data in area 1 in order to single out the intensity of upstream dust influence.

In order to map the general evolution of the dust events, composite plots of synoptic meteorological situations (Fig. 2) have been done for the 54 dust events. About 2 days before the hour 0 , a cold high is centered on $\left(45^{\circ} \mathrm{N}\right.$, 
$\left.90^{\circ} \mathrm{E}\right)$ with an active low pressure cyclone at $\left(40^{\circ} \mathrm{N}\right.$, $120^{\circ} \mathrm{E}$ ). Cold and dry air moves from Mongolia into China and triggers a dust storm over the Gobi desert area (Liu et al., 2004), while a front is developed from the cyclone center toward southern China. One day later, the frontal line has passed over Taiwan with the cold high moving southeastward to central China. After then, the anticyclone shifts eastward to the East China Sea. Over Taiwan, northeasterlies prevail after the passage of the cold front and then gradually change to be easterlies. Along the western side, northerlies are strong along the coast, but getting weaker toward inland. The Central Mountain Range not only makes slow the air flow, but also blocks the moisture from being transported southwestward. Each year during September-April, the dry and stagnant climate over most of western Taiwan is accompanied by a higher level of PM10 concentration (Yang, 2002).

Meanwhile, composite plots of the backward air parcel trajectories shown in Fig. 3 help to verify whether dust particles have originated in the lower tropospheric region over northern China and Mongolia 2 or 3 days earlier than the hour 0 . Two days earlier, air parcels are located near $\left(38.5^{\circ} \mathrm{N}, 110^{\circ} \mathrm{E}\right)$ within an elliptic region whose major and minor axes are about $8^{\circ}$ and $6^{\circ}$, respectively, at about $800-3200 \mathrm{~m}$ above the sea level. Historically, this area is known to see frequent occurrence of major dust storms (Liu et al., 2004). Certainly, dust particles could also come within 3 to 4 days from the deserts in the Xingjiang province, located on the northwestern corner of China. In this section, each backward air parcel trajectory was calculated by using the NOAA ARL HYSPLIT Model with NCEP reanalysis datasets (http://www.arl.noaa.gov/ready/hysplit4.html).

\section{General characteristics}

On average, four to five dust events happen each year with a significant interannual variability (Fig. 4). A maximum of eight events was observed in 2000 and 2001, though a minimum of one was recorded in 1996, 1997, 1998 and 2005. Since each event can last longer than 1 day, an average of 6.1 dust days is observed each year. Year 2000 had the maximum number of 12 dust days. In the meantime, during winter of 2003 (i.e. December 2003-February 2004), there were 11 dust days, versus three in spring 2004. In contrast, in 2000, 11 dust days occurred in spring, with only one in winter 1999. Such seasonal and interannual variation must be associated with different synoptic systems. The implication for the Taiwan EPA is to start monitoring the occurrences of dust storms in mainland China and their possible influence on local air quality starting in De- cember rather than March, as is usually expected (Young et al., 1997). Although, among the 73 dust days, the monthly maximum occurrence frequency of $23.3 \%$ is in March and the days with rank 4 or 5 have only occurred in March and April.

By taking the first peak hour of each event at Wanli as the hour 0 , we can rearrange the whole dataset to obtain a composite temporal variation of air quality at each station. Fig. 5 shows the hourly maximum, 95, 75, 50 and 25 percentiles, minimum and mean PM10 levels at Wanli at hours between 2 days before and 4 days after the hour 0 . The maximum peak concentration ever measured is $586 \mu \mathrm{g} \mathrm{m}^{-3}$ at 18LT 12 March 1995. Rarely, the second peak level is higher than the first one, except for the case of $501 \mu \mathrm{g} \mathrm{m}^{-3}$ at 03LT 28 April 2000 and $434 \mu \mathrm{g} \mathrm{m}^{-3}$ at 13LT 27 April 2000. In Table 1, the mean value of the three highest PM10 levels in area 1, which is different slightly from that observed at Wanli but shows a similar feature is shown. On average, a single-peak pattern that is about four times the pre-event level dominates with a mean peak level of $206 \mu \mathrm{g} \mathrm{m}^{-3}$. The PM10 concentration rises about $12 \mathrm{~h}$ before the hour 0 and decreases to the starting level about $36 \mathrm{~h}$ after. Similar patterns with a peak level of $232 \mathrm{\mu g} \mathrm{m}^{-3}$ and $160 \mu \mathrm{g} \mathrm{m}^{-3}$ are also seen in the hourly plots of 75 and 25 percentiles, respectively.

To illustrate the evolution of chemical species simultaneously, the hourly variation of the normalized mean $\mathrm{NO}_{\mathrm{x}}, \mathrm{CO}, \mathrm{O}_{3}, \mathrm{PM} 10$ and wind speed at Wanli $\left(\mathrm{A}_{1}\right)$, Chunsam $\left(\mathrm{B}_{3}\right)$ and Kuting $\left(\mathrm{B}_{4}\right)$ at hours between 2 days before and 2 days after the hour 0 are plotted in Fig. $6 \mathrm{a}-\mathrm{c}$. The selections of Chunsam and Kuting stations which are downstream of Wanli in northeasterly flow (Fig. 1) and where the wind speed is only about $1-3 \mathrm{~m} \mathrm{~s}^{-1}$ versus that of 3-7 $\mathrm{m} \mathrm{s}^{-1}$ at Wanli reveal the situation in the Taipei basin. Meanwhile, the levels of $\mathrm{NO}_{\mathrm{x}}$ and $\mathrm{CO}$ at these two stations are about $30-80 \mathrm{ppbv}$ and $0.5-$ 1.5 ppmv, respectively, versus $5-18$ ppbv and $0.3-$ 0.5 ppmv, respectively, at Wanli, where anthropogenic emission sources are sparse. The levels of these species are suppressed during the period of strong wind speed, which is about 1 day before and after the hour 0 . However, the PM10 levels at these three stations all increase simultaneously with the increase of wind speed, though the peak value occurs a few hours later than that of the wind speed. Hence, it is clear that the aerosols causing the rise in PM10 concentrations are transported from upstream sources. The peak PM10 level is higher at Wanli than in the Taipei basin.

Another chemical species that shows a similar variation pattern to that of PM10 is ozone, the level of which also increases with the wind speed before the hour 0 and drops after then. At Wanli, the peak ozone 

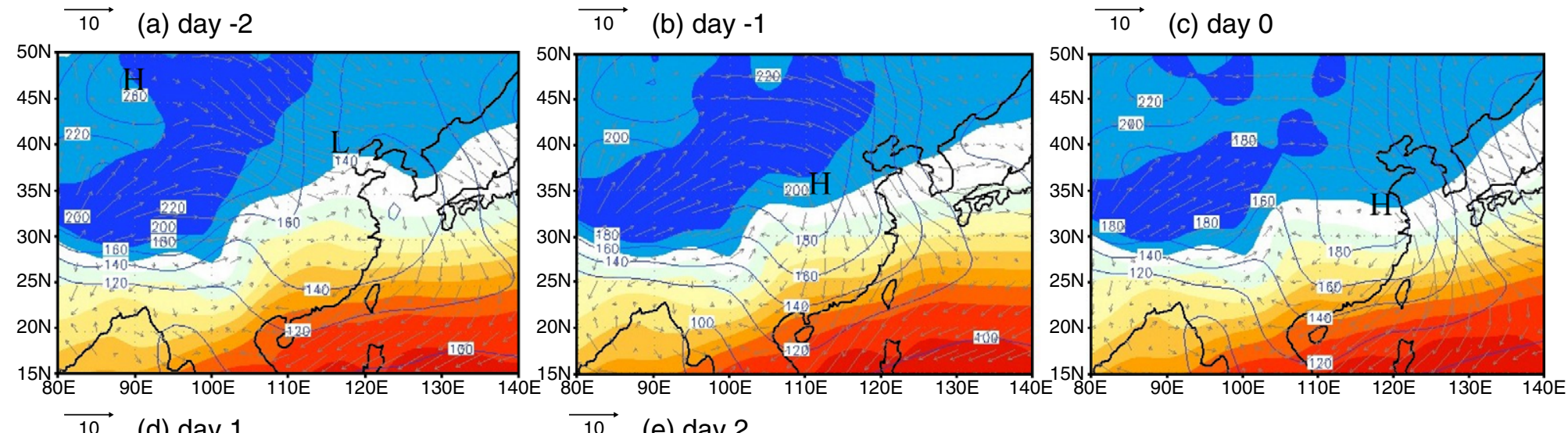

$\overrightarrow{10}$ (e) day 2

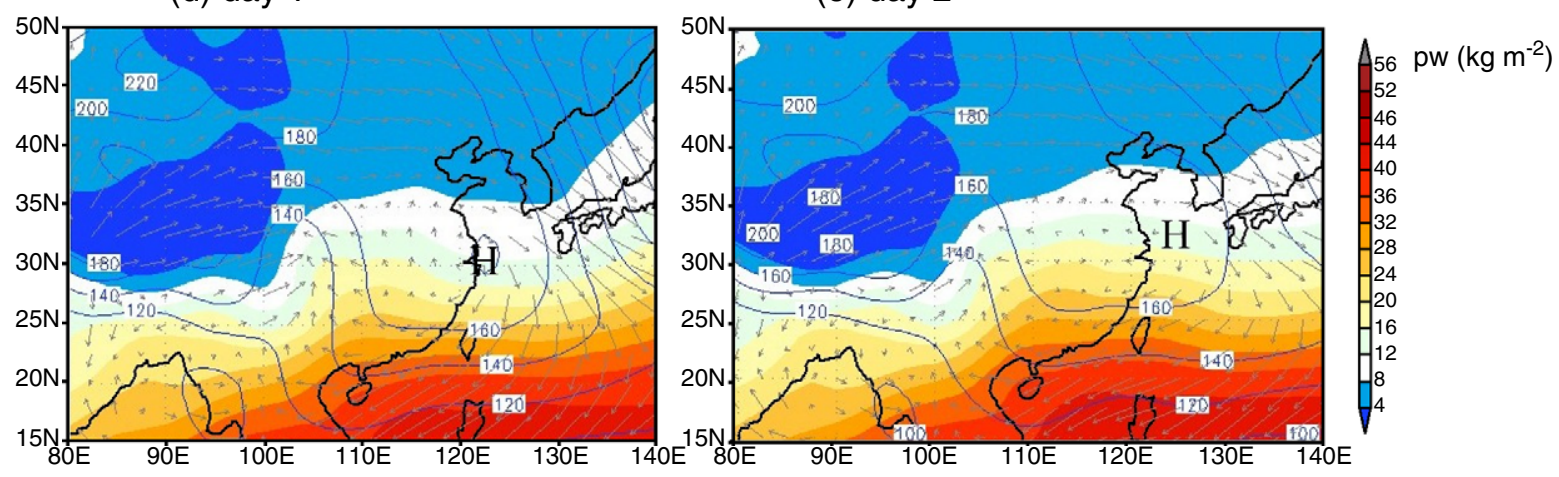

Fig. 2. Composite plots of the contours of geopotential height (m), color shaded areas of precipitable water ( $\mathrm{pw}, \mathrm{kg} \mathrm{m}^{-2}$ ) and wind flow at $1000 \mathrm{hPa}$ on (a) 2 days earlier, (b) 1 day before, (c) the hour 0 , i.e. the peak PM10 concentration occurring hour at Wanli $\left(A_{1}\right)$ or Yanming $\left(A_{2}\right)$, (d) 1 day after and (e) 2 days after the hour 0 . 
(a)

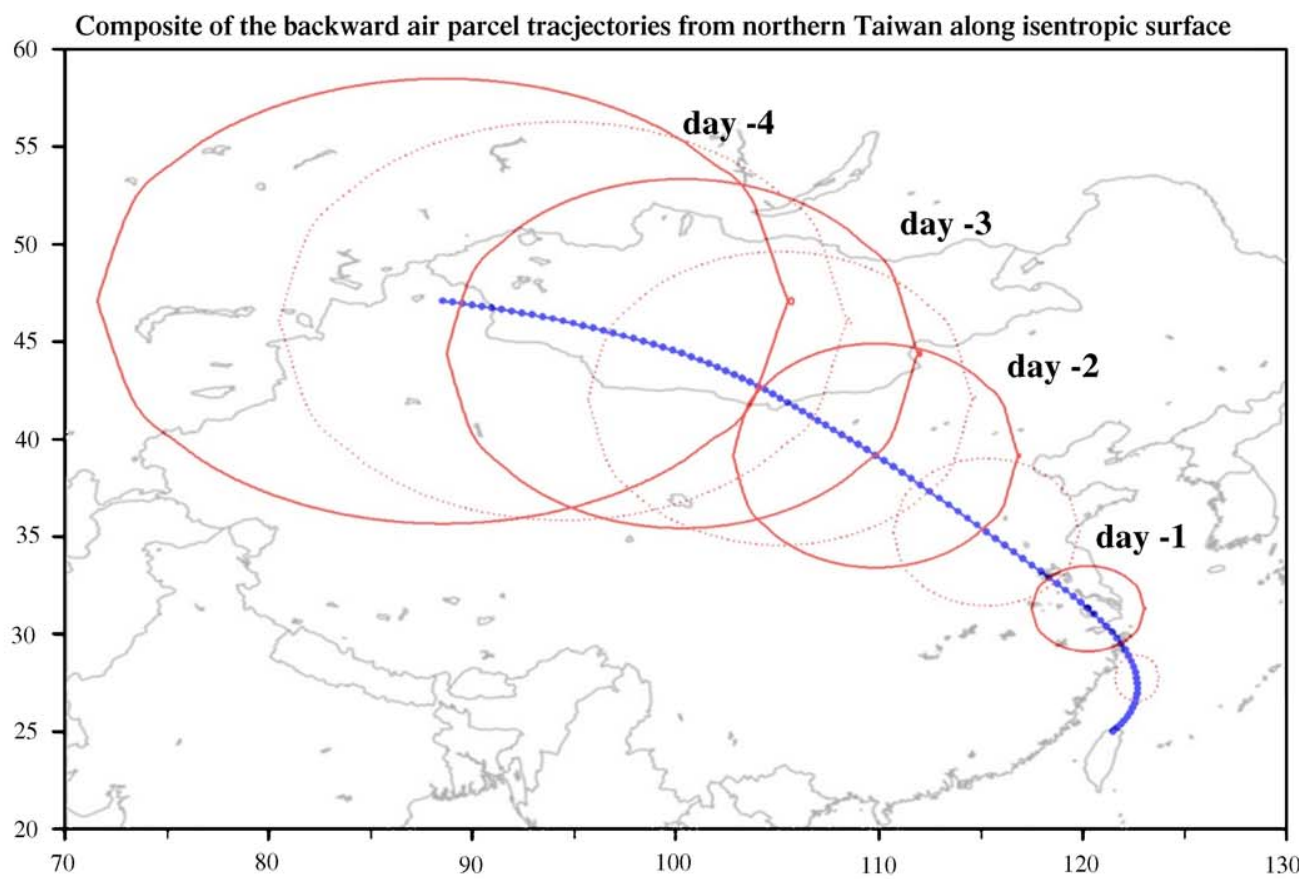

(b)

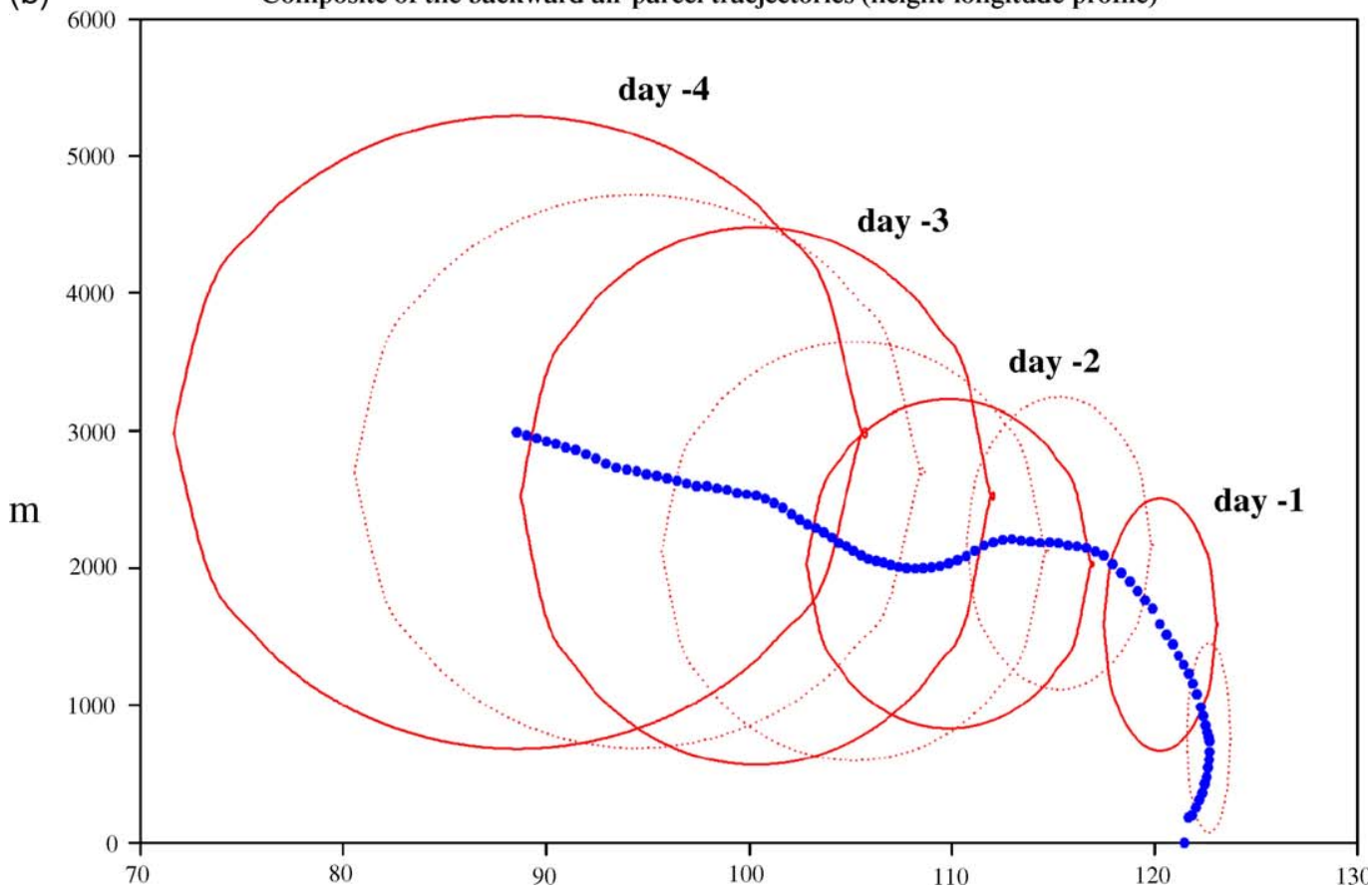

Fig. 3. Composite plots of the backward air parcel trajectories from northern Taiwan on a (a) latitude-longitude and (b) height-longitude profile. In these figures, the dot line represents the averaged trajectory of air parcels backward traced starting from the hour 0 of each dust event in 1994-2005. The solid circle covers all locations that air parcel may originate from on 1, 2, 3 or 4 days earlier, while the dashed circles are for every half days. In this figure, all backward air parcel trajectories were calculated by using the NOAA ARL HYSPLIT Model with NCEP reanalysis datasets (http:// www.arl.noaa.gov/ready/hysplit4.html).

level reaches about 60 ppbv, while it is about 30 ppbv at Chungsam and Kuting owing to the titration of NO (Liu et al., 2002; Liu and Liu, 1991).
Among the 73 dust days, 26 of them are with PSI larger than 100 in area 1, i.e. unhealthy condition for people. The unhealthy occurrence frequency of $36 \%$ is mainly due to 
No. of dust events observed in Taiwan

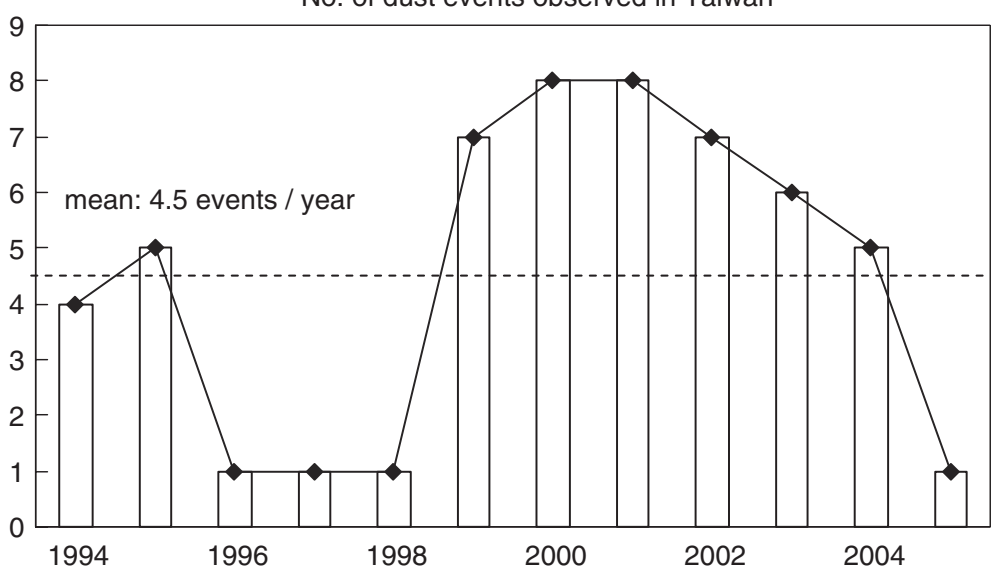

Fig. 4. Annual variation of the number of dust events observed in Taiwan during 1994-2005.

PM10. On average, there are 2.2 dust days with PSI larger than 100 each year. Among those 21 monitoring stations in area 1 , the ever recorded highest PSI value of $166-171$ occurred on 27 April 2000. The average occurrence frequency of PSI larger than 100 on a dust day is about $14 \%$ at each station, while Wanli has the highest frequency of $26 \%$ whereas the lowest of $3.8 \%$ is at Yanming. In metropolitan Taipei, the occurrence frequency ranges between $15 \%$ and $21 \%$, while it is about $8 \%$ in Ilan ( $F_{1}$ in Fig. 1$)$ and $9 \%$ in Hualien ( $F_{2}$ in Fig. 1) on the eastern coast.

Within the 26 dust days with PSI larger than 100, 9 days have rank 1, 10 have rank 2, 4 have rank 3, 1 has rank 4 and 2 have rank 5 . The chance of observing dust days with PSI larger than 100 is $23 \%$ for rank 1, $42 \%$ for rank $2,57 \%$ for rank 3 and $100 \%$ for both ranks 4 and 5 . Clearly, the higher the dust rank, the higher is the possibility of registering unhealthy air quality. This information is rather useful. Officials can actually concentrate on forecasting the dust rank of each event and thus warn the public about the probability of unhealthy condition well in advance based on these statistics.

\section{Air quality island-wise}

Through a composite analysis, we can analyze the spatial distribution of $95,85,75$ and 50 percentiles, and mean value of the PM10 concentration at the hour 0 (Fig. 7). The highest PM10 concentration occurs over the northern coast region extending southward and eastward along the shoreline. At the central and southern sections of the west coast, the chance of observing a peak PM10 level higher than $150 \mu^{-3} \mathrm{~m}^{-3}$ is lower than $50 \%$, while the chance of observing $175 \mu \mathrm{g} \mathrm{m}^{-3}$ is lower than $10 \%$. Meanwhile, there is no chance at all to observe peak PM10 level higher than $150 \mu \mathrm{g} \mathrm{m}^{-3}$ at the southeastern and southern tip of Taiwan. At the most polluted southwestern corner, a regional higher value center always appears; however, this center might not be

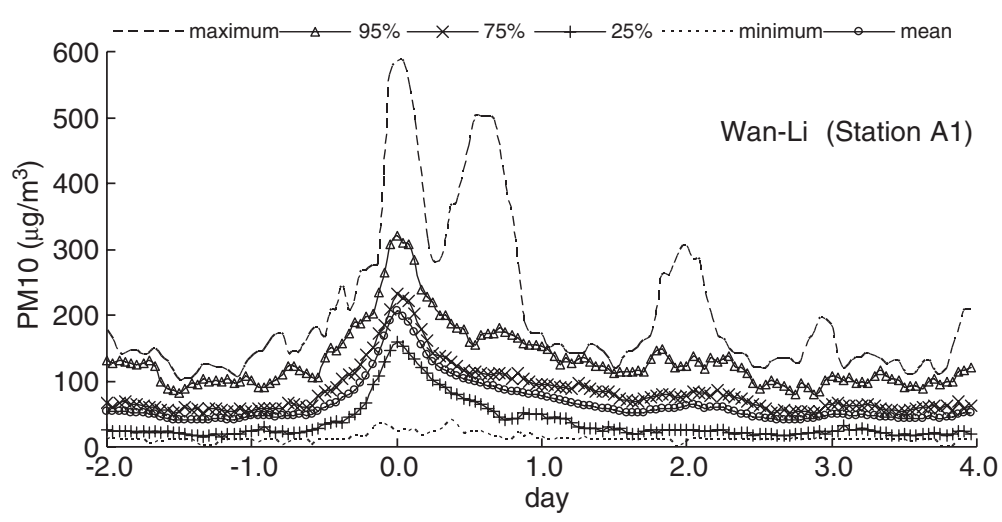

Fig. 5. Composite plots of the variation of the hourly maximum, 95, 75, 50 and 25 percentiles, minimum and mean PM10 levels at Wanli at hours between 2 days before and 4 days after the hour 0 at Wanli. 

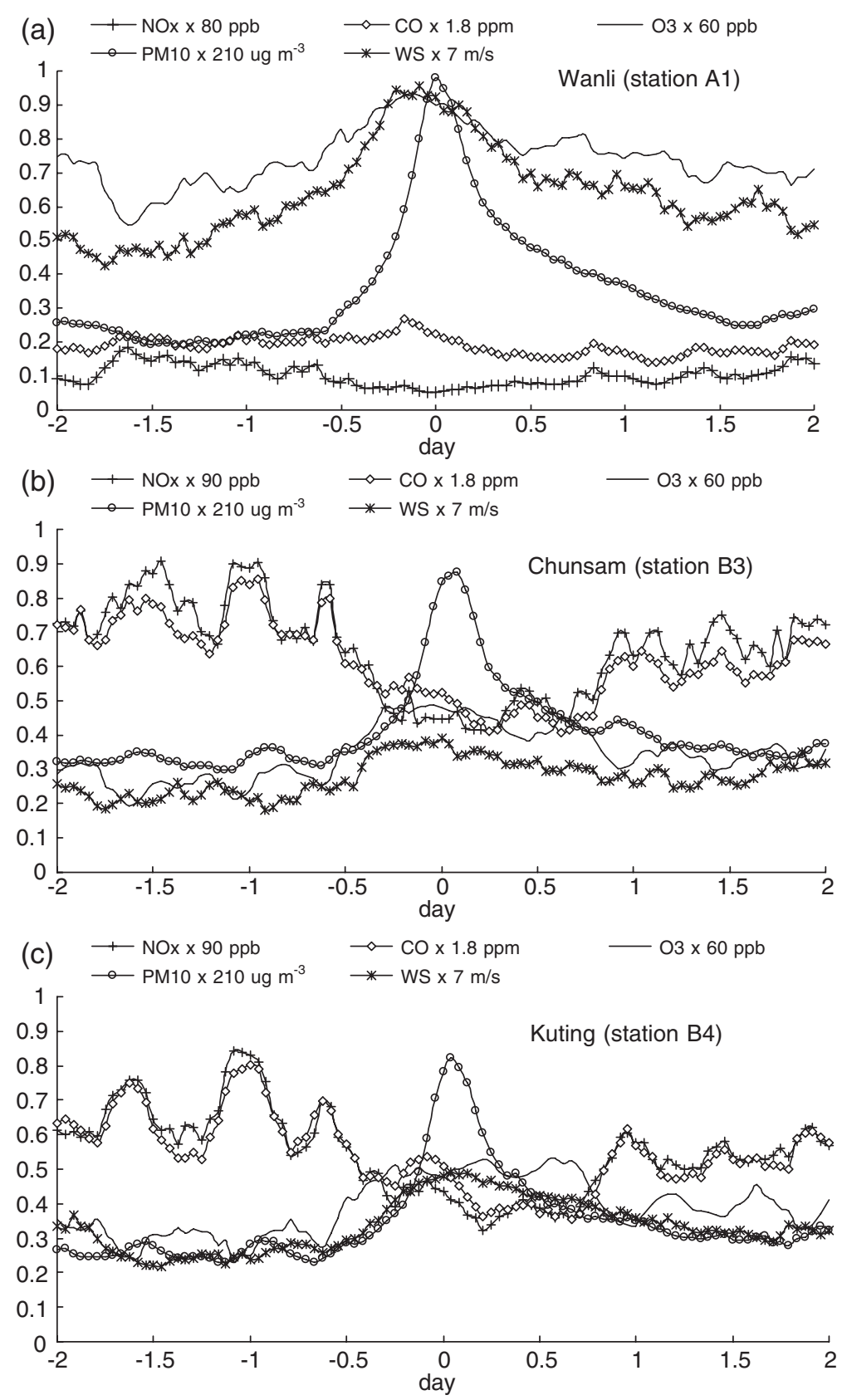

Fig. 6. Composite plots of the hourly variation of the normalized mean $\mathrm{NO}_{\mathrm{x}}, \mathrm{CO}, \mathrm{O}_{3}, \mathrm{PM} 10$ and wind speed at (a) Wanli $\left(\mathrm{A}_{1}\right)$, (b) Chunsam $\left(\mathrm{B}_{3}\right)$ and (c) Kuting $\left(\mathrm{B}_{4}\right)$ at hours between 2 days before and 2 days after the hour 0 .

associated with the dust influence, but rather be attributed to local pollution.

Meanwhile, Fig. 8 shows the temporal variation of the mean PM10 level at stations $\mathrm{A}_{1}-\mathrm{F}_{4}$ (Fig. 1) during the hours of the 2 days before and the 4 days after the hour 0 . At Wanli (station $\mathrm{A}_{1}$ ), dust influence can be detected $12 \mathrm{~h}$ before the hour 0 and last for $48 \mathrm{~h}$. As for other stations in the northern Taiwan (stations $\mathrm{B}_{1}-\mathrm{B}_{5}$ and $\mathrm{C}_{1}-\mathrm{C}_{5}$ ), dust particles arrive probably $12 \mathrm{~h}$ before the hour 0 and last about $24 \mathrm{~h}$. Meanwhile, the peak PM10 level at central and southern Taiwan (stations $\mathrm{D}_{1}-\mathrm{D}_{5}$ and $\mathrm{E}_{1}-\mathrm{E}_{5}$ ) occurs about $3-12 \mathrm{~h}$ after the hour 0 and the dust influencing period is shorter than $12 \mathrm{~h}$. On the east coast, the peak PM10 hour at Hwalien (station $\mathrm{F}_{2}$ ) is about $6 \mathrm{~h}$ after the hour 0 with a dust influencing period also shorter than $12 \mathrm{~h}$. In general, the peak PM10 levels at central $\left(D_{1}-D_{5}\right)$, southern 

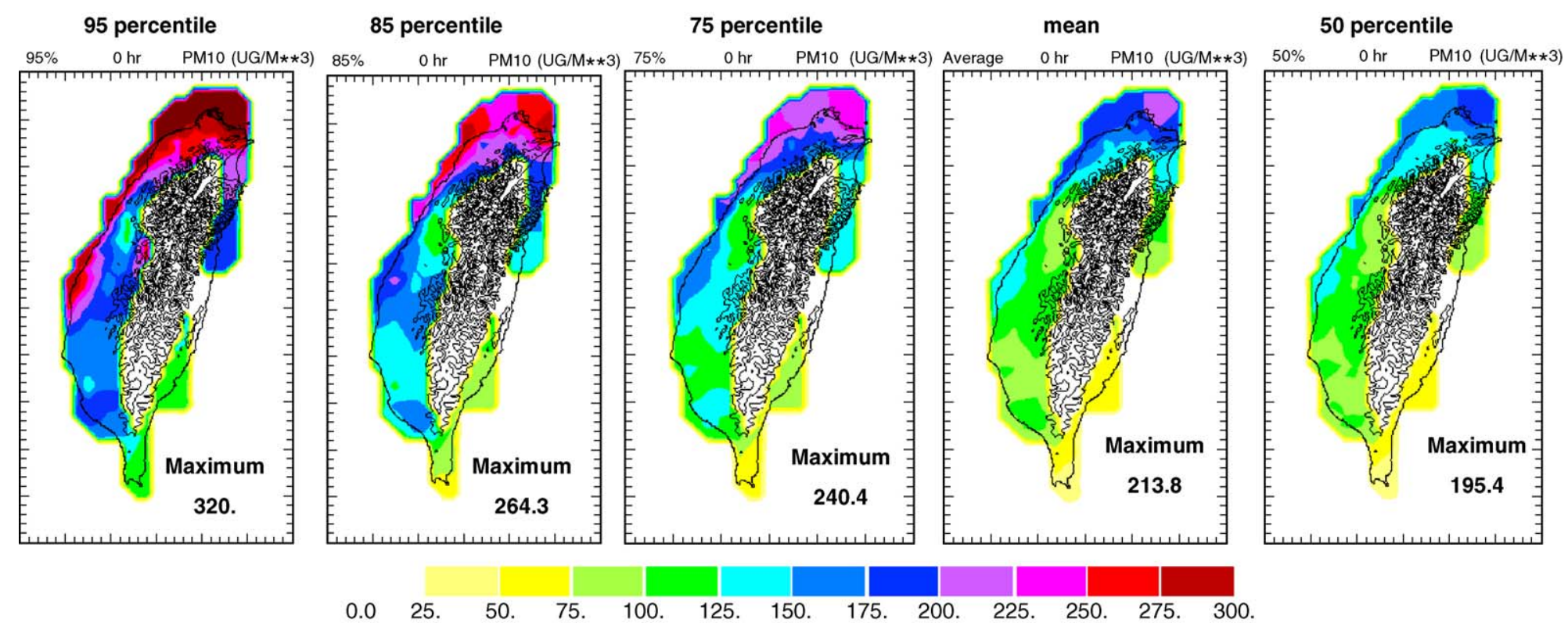

Fig. 7. Spatial distribution of the $95,85,75$ and 50 percentiles and the mean PM10 concentration $\left(\mu \mathrm{g} \mathrm{m}^{-3}\right)$ on the hour 0 . 

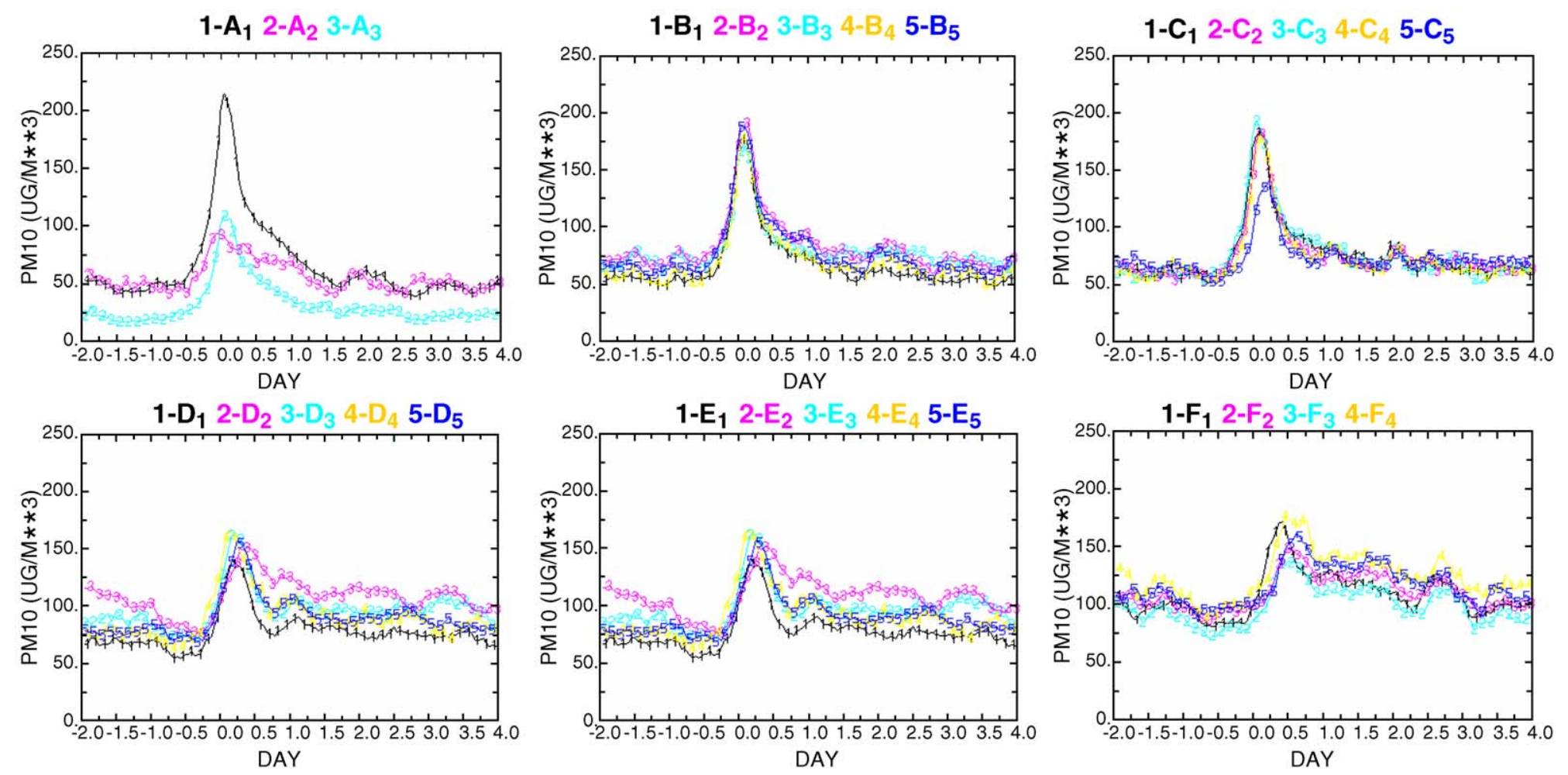

Fig. 8. Hourly variation of mean PM10 level at hours between 2 days before and 4 days after the hour 0 at stations $A_{1}-F_{4}$ (marked in Fig. 1). 


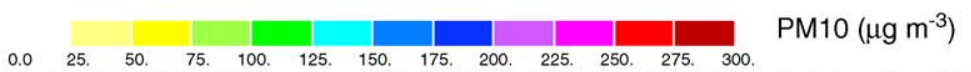
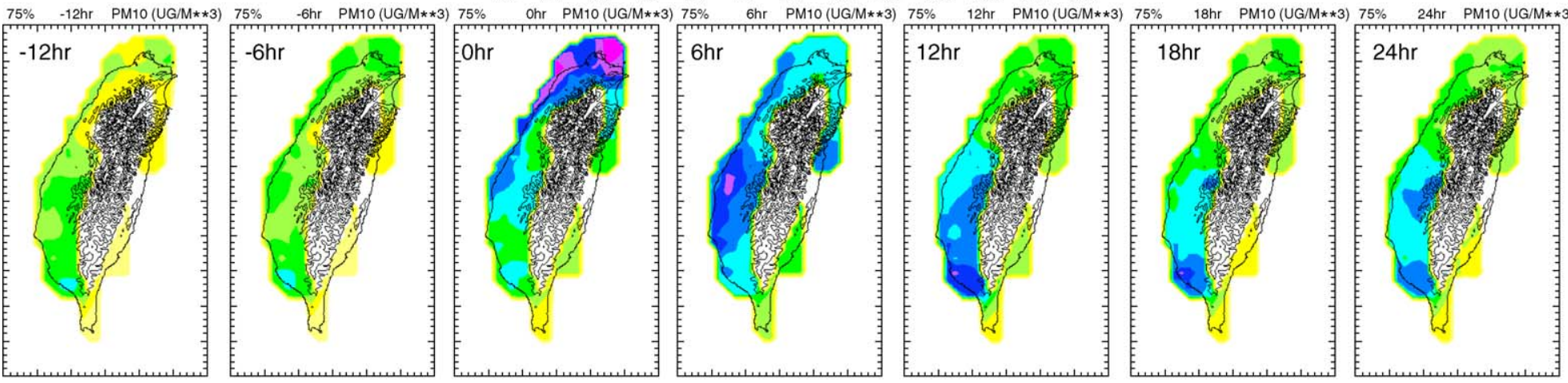

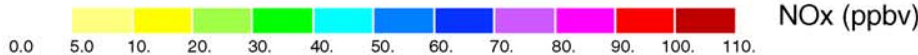
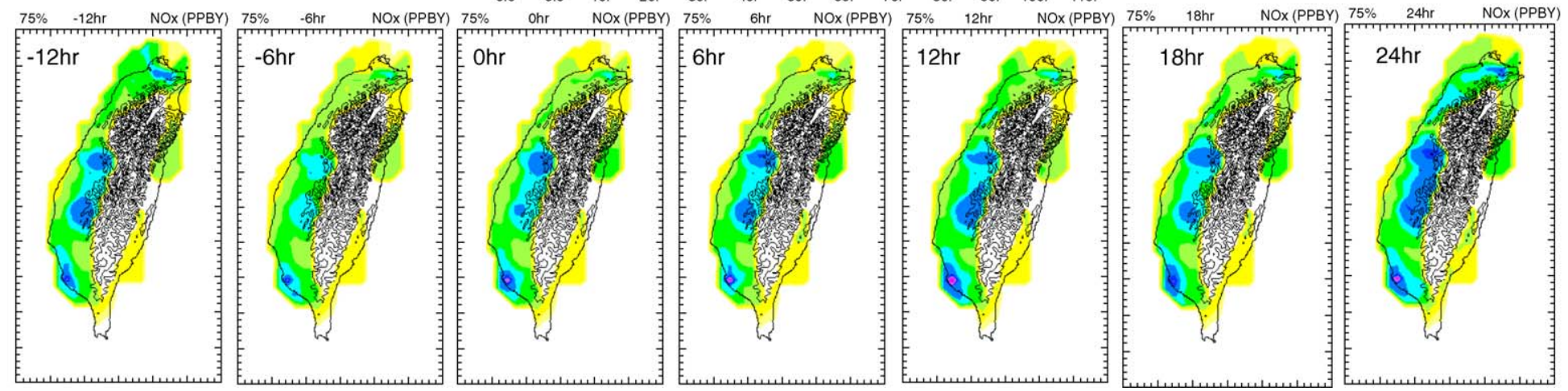

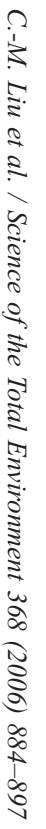

Fig. 9. Spatial variation of the 75 percentile of PM10 and $\mathrm{NO}_{\mathrm{x}}$ concentration at 12 and $6 \mathrm{~h}$ before, at the hour 0 and at $6,12,18$ and $24 \mathrm{~h}$ after the hour 0 . In this figure, some areas are leaving blank, due to no measurement data nearby, particularly in the central mountain range. Meanwhile, at the southern tip, $\mathrm{NO}_{\mathrm{x}}$ concentration remains at a low level. 
$\left(\mathrm{E}_{1}-\mathrm{E}_{5}\right)$ and eastern Taiwan $\left(\mathrm{F}_{1}-\mathrm{F}_{2}\right)$ are lower than those in northern Taiwan $\left(\mathrm{A}_{1}, \mathrm{~B}_{1}-\mathrm{B}_{5}, \mathrm{C}_{1}-\mathrm{C}_{5}\right)$, just as expected.

The off-shore island station Martsu (station $\mathrm{A}_{3}$ ) is located to the north of Taiwan and close to the mainland China coast. Many times, this site observes dust signals similar to those at Wanli. Still, it is more reasonable to use Wanli as the dust identification site for events occurring on Taiwan Island. In the meantime, Taitung $\left(\mathrm{F}_{3}\right)$ and Hengchung $\left(\mathrm{F}_{4}\right)$, at the southeastern and southern corner, observed the lowest PM10 level among all air quality stations (Fig. 8).

To get a better view of the spatial and temporal variation of the PM10 concentration over Taiwan, the spatial distribution of the 75 percentile at 12 and $6 \mathrm{~h}$ before, at the hour 0 , and at $6,12,18$ and $24 \mathrm{~h}$ after, is shown in Fig. 9. Meanwhile, to get a better understanding of the local pollution condition, composite plots of the 75 percentile of $\mathrm{NO}_{\mathrm{x}}$ level are also shown in Fig. 9. In general, before the hour 0, a peak PM10 level appears at the southwestern corner where the amount of anthropogenic pollutants emission is not negligible. At the hour 0 , the dust signal is the strongest and areas with higher PM10 level appear mostly in northern Taiwan. Six hours after the hour 0 , such areas are shifting to the central western coast regions, and then gradually move southward along the west coast, while at the same time another high value area moves to the east coast, with a decreasing concentration. The southward shifting of the peak PM10 areas probably results from a mixture of upstream dust particles and local pollutants, as the peak NOx areas are mainly located on the western plain.

\section{Conclusion}

According to Yang (2002), who analyzed the hourly PM10 data during 1994-1999 in order to reveal the spatial and seasonal variations of PM10 concentrations in Taiwan, the highest monthly mean level of $60-70 \mu \mathrm{g} \mathrm{m}^{-3}$ at northern sites that occurs in March-May is attributed to dust transport from central Asia. As for the southwestern and southern regions, seasonal variations of regional airflow, precipitation and temperature result in an efficient accumulation of local aerosol in winter and cleaner conditions in summer. Yen (2003) also confirmed these phenomena in datasets collected during 1994-2002 and noted a steady decreasing trend of the percentages of the days with PSI larger than 100 island-wise, i.e. from $6.8 \%$ down to $2.8 \%$. Hence, if local pollution conditions have been controlled efficiently, then it becomes easier to identify signals of each dust event and to set up a standard procedure based on the past climatological pattern and thus be able to warn the public efficiently and in advance.
During 1994-2005, there have been 54 dust events and 73 dust days. Each event may last longer than 1 day and is characterized by a surplus of PM10 concentration. On average, 4.5 dust events and 6.1 dust days occur each year. For each dust day, there is a $36 \%$ chance of it being unhealthy, i.e. PSI larger than 100, mainly due to PM10 in area 1 (Fig. 1) where one-third of the nation's population resides. Based on the ranking methodology described in Section 2, 86\% of these dust days have a dust rank of either 1 or 2. For days with ranks 1, 2, 3, 4 and 5 , the chances of observing air quality as being unhealthy are $23 \%, 41 \%, 57 \%, 100 \%$ and $100 \%$, respectively, i.e. the higher the rank, the higher the probability. Among the 21 air quality monitoring stations in area 1, Wanli $\left(\mathrm{A}_{1}\right.$ in Fig. 1) has the highest chance $(26 \%)$ of being unhealthy in association with dustfalls.

In 2000, there were a total of 12 dust events with only one event occurring in winter, whereas in 2004 there were 14 events with 11 occurring in winter. Clearly, besides a significant annual variation of dust events (Fig. 4), effects of the seasonal variation of the synoptic weather system on the occurrence of dust storms and the transport of dust particles toward the Taiwan region are worthy to be studied (Liu et al., 2004). Although the experience in 2004 suggests that Taiwan EPA should start monitoring the influence of Asian dust storms in December every year, the highest monthly occurrence frequency is in March, which is $23.3 \%$, and events with ranks 4 and 5 have occurred in March and April only.

Analysis of the temporal and spatial variation of the PM10 level indicates that each dust event starts about $12 \mathrm{~h}$ ahead of the hour 0 and lasts for about $36 \mathrm{~h}$ after the dust arrival. Then, approximately $3-12 \mathrm{~h}$ after the hour 0 , the high PM10 level area shifts to the eastern coast and to the central and southern sections of western Taiwan. The high PM10 concentration on the east coast is associated with long-range transported dust, but the high PM10 concentration at the western side is due to a mixture of dust particles and local pollutants.

The developed dust intensity rank (DIR) with PSI is useful in linking each dust event to a local environmental index. It is applicable not only for the dust event forecasting system but also for a systematic analysis of past events. Furthermore, it can also assist with the intercomparison of dust influences on air quality at different downstream regions.

\section{Acknowledgement}

This research was supported by the National Science Council grants NSC92-2621-Z-002-026 and NSC94- 
2111-M-002-008, and the Environmental Protection Administration grant EPA-93-L105-02-206 of R.O.C. The authors would like to thank Taiwan EPA and the Central Weather Bureau for providing all necessary data for analysis. We also appreciate the convenience of using the on-line HYSPLIT model developed by US NOAA Air Resources Laboratory. Detailed editing by Ms. Marcella Valka and Dr. Sahara Paul is highly appreciated.

\section{References}

Akimoto H, Mukai H, Nishikawa M, Murano K, Hatakeyama S, Liu $\mathrm{CM}$, et al. Long-range transport of ozone in the east Asia Pacific rim region. J Geophys Res 1996;101:1999-2010.

Chen YS, Lim JY. The recent characteristics of Asian dust and haze events in Seoul, Korea. Meteorol Atmos Phys 2004;87:143-52.

Chen YS, Sheen PC, Chen ER, Liu YK, Wu TN, Yang CY. Effects of Asian dust storm events on daily mortality in Taipei, Taiwan. Environ Res 2004;95:151-5.

Chung YS, Kima HS, Dulama J, Harris J. On heavy dustfall observed with explosive sandstorms in Chongwon-Chongju, Korea in 2002. Atmos Environ 2003;37:3425-33.

Fang M, Zheng M, Wang F, Chim KS, Kot SC. The long range transport of aerosols from northern china to Hong Kong - a multitechnique study. Atmos Environ 1999;33:1803-17.

Fang GC, Chang CN, Wu YS, Lu SC, Fu PPC, Chang SC, et al. Concentration of atmospheric particulates during a dust storm period in central Taiwan, Taichung. Sci Total Environ 2002;287:141-5.

Kim YJ, Kim KW, Oh SJ. Seasonal characteristics of haze observed by continuous visibility monitoring in the urban atmosphere of Kwangju, Korea. Environ Monit Assess 2001;70:35-46.

Korea Meteorological Administration (KMA). Guidance for Meteorological Observation on Ground; 2002.

Kwon HJ, Cho SH, Chun Y, Lagarde F, Pershagen G. Effects of the Asian dust events on daily mortality in Seoul, Korea. Environ Res Sec A 2002;90:1-5.

Lee YC, Hill PR. Cool season pollution episodes in Hong Kong, 1996-2002. Atmos Environ 2003;37:2927-39.
Lei YC, Chan CC, Wang PY, Lee CT, Cheng TJ. Effects of Asian dust event particles on in ammation markers in peripheral blood and bronchoalveolar lavage in pulmonary hypertensive rats. Environ Res 2004;95:71-6.

Lin TH. Long-range transport of yellow sand to Taiwan in Spring 2000: observed evidence and simulation. Atmos Environ 2001;35:5873-82.

Lin NH, Peng CM. A semi-quantitative scheme for estimating the contribution of below-cloud scavenging by raindrops based on observations of cloud chemistry at a mountain site in Taipei, Taiwan. Terr Atmos Ocean Sci 1999;10:693-704.

Liu CM, Feng TS. Atmospheric turbidity over Taiwan. Atmos Environ 1990;24A:1303-12.

Liu CM, Liu SC. A study of the winter surface ozone in Taipei. J Meteorol Soc Jpn 1991;69:161-9.

Liu CM, Buhr M, Merrill JT. Ground-based observation of ozone, carbon monoxide and sulfur dioxide at Kenting, Taiwan during PEM WEST (B) campaign. J Geophys Res 1997;102:28,613-26.

Liu KY, Wang Z, Hsiao LF. A modeling of the sea breeze and its impacts on ozone distribution in northern Taiwan. Environ Model Softw 2002;17:21-7.

Liu CM, Qian ZA, Wu MC, Song MH, Liu JT. A composite study of synoptic differences between major and minor dust storms springs over the China-Mongolia areas. Terr Atmos Ocean Sci 2004;15:999-1018.

Qian ZA, He HX, Qu Z, Chen MD. Classification criteria, listing of events and statistical characteristics of dust storms in northwest China. In: Fang ZY, Zhou FK, Jiang JX, Qian ZA, editors. China Dust Storm Research. China Meteorological Press; 1997. p. 1-10 [in Chinese].

Qian W, Quan L, Shi S. Variations of the dust storm in China and its climatic control. J Climate 2002;15:1216-29.

Yang KL. Spatial and seasonal variation of PM10 mass concentrations in Taiwan. Atmos Environ 2002;36:3403-11.

Yen YL. Long-term air quality trend analysis and editing of an annual report; 2003. EPA92-FA11-03-A029, 411 pp. [in Chinese].

Young CY, Lee KH, Liu CM. A comparison of air-quality data obtained during a dust-storm event and a local pollution episodeMarch 12-16, 1995. J Chinese Environ Protection Society ROC, vol. 20. 1997. p. 1-38 [in Chinese]. 